\title{
Identification of CETP as a molecular target for estrogen positive breast cancer cell death by cholesterol depleting agents
}

\author{
Luke Esau$^{1}$, Sunil Sagar ${ }^{1}$, Dhinoth Bangarusamy², Mandeep Kaur ${ }^{1,3}$ \\ ${ }^{1}$ King Abdullah University of Science and Technology (KAUST), Computational Bioscience Research Center, Thuwal, Kingdom \\ of Saudi Arabia \\ ${ }^{2}$ King Abdullah University of Science and Technology (KAUST), Bioscience Core Lab, Thuwal, Kingdom of Saudi Arabia \\ ${ }^{3}$ School of Molecular and Cell Biology, University of the Witwatersrand, Private Bag 3, Wits, Johannesburg, South Africa \\ Correspondence to: Mandeep Kaur, email: mandeep.kaur@wits.ac.za \\ Keywords: CETP, cholesterol depletion, breast cancer, acetyl plumbagin \\ Received: August 15, $2016 \quad$ Accepted: October 30, $2016 \quad$ Published: November 03, 2016
}

\section{ABSTRACT}

Cholesterol and its metabolites act as steroid hormone precursors, which promote estrogen receptor positive (ER+) breast cancer (BC) progression. Development of cholesterol targeting anticancer drugs has been hindered due to the lack of knowledge of viable molecular targets. Till now, Cholesteryl ester transfer protein (CETP) has been envisaged as a feasible molecular target in atherosclerosis, but for the first time, we show that CETP contributes to BC cell survival when challenged with cholesterol depleting agents. We show that MCF-7 CETP knockout BC cells pose less resistance towards cytotoxic compounds (Tamoxifen and Acetyl Plumbagin (AP)), and were more susceptible to intrinsic apoptosis. Analysis of differentially expressed genes using Ingenuity Pathway Analysis (IPA), in vivo tumor inhibition, and in vitro phenotypic responses to AP revealed a unique CETP-centric cholesterol pathway involved in sensitizing ER+ BC cells to intrinsic mitochondrial apoptosis. Furthermore, analysis of cell line, tissue and patient data available in publicly available databases linked elevated CETP expression to cancer, cancer relapse and overall poor survival. Overall, our findings highlight CETP as a pharmacologically relevant and unexploited cellular target in BC. The work also highlights AP as a promising chemical entity for preclinical investigations as a cholesterol depleting anticancer therapeutic agent.

\section{INTRODUCTION}

Clinical and experimental investigations evidence an unquestionable role for cholesterol in cancer progression [1]. This link is supported by multiple studies documenting levels of HDL and LDL in cancer patients [2-4], enhanced cholesterol synthesis in cancer cells [5-7], cholesterol accumulation in lipid rafts $[8,9]$, steroidogenesis in cancer cells $[10,11]$, over-expression of cholesterol transport receptors: SR-B1 (HDL) and LDL-receptor [12, 13], and more recently, the involvement of the cholesterol metabolite 27HC [14-16]. Thus the precedent has been set for developing cholesterol-modulating anticancer agents [17-19].

Breast cancer (BC) is a complex disease driven by lifestyle, genetics, and the abnormal function of hormones [20]. Dietary cholesterol [13] and particularly lipoproteins (both LDL and HDL) have been shown to fuel growth of breast tumours [20,21], therefore a better understanding of cholesterol homeostasis for future $\mathrm{BC}$ therapeutics is necessary. The cholesteryl ester transfer protein (CETP) shuttles cholesteryl esters (CEs) and triglycerides between HDL and LDL to maintain cholesterol homeostasis both intracellularly and extracellularly [22]. CETP has been shown to prevent development of atherosclerotic lesions in ovariectomized hypercholesterolemic mice [23], and a link between CETP and estrogen has also been proposed [24]. Furthermore, CETP-deficient cells have been reported to have lower cholesterol content as CETP deficiency impeded CE transport from its site of synthesis to the storage droplet thereby reducing $\mathrm{CE}$ hydrolysis [25]. Inhibiting CETP was envisaged as a viable strategy to prevent coronary heart disease [26], and despite leading to several failed clinical trials its role in cancer has been overlooked. This biological paradigm calls for reevaluation of the biological functions of CETP in diseases. 
In the present study, we present a small molecule, acetyl plumbagin (AP), with cholesterol modulatory features and evidence of CETP as a cell survival gene that facilitates $\mathrm{BC}$ proliferation and resistance to apoptosis.

\section{RESULTS}

\section{In vitro and in vivo anticancer effects of $\mathrm{AP}$}

Our previous study highlighted AP (a derivative of PL) as a potential anticancer lead molecule [27]. AP was selected for further in vitro and in vivo investigations based on key characteristics including: its low in vitro toxicity towards normal skin fibroblast BJ cells and its selective activation of caspase and apoptosis pathways in MCF-7 cells compared to BJ and triple negative BT20 cells. The chronology of apoptosis induction was determined by measuring cell viability, mitochondrial outer membrane potential (MOMP), apoptosis staining and apoptosis markers by western blot analysis in MCF7 cells treated with AP (PL was used as the parent drug control). MCF-7 viability was reduced as early as $2 \mathrm{~h}$ and continued to decrease with time in response to PL and AP treatment (Figure 1A). Consistent with reduced viability, we observed MOMP collapse within 1 hour (Figure 1B) and apoptosis induction at 2 and $6 \mathrm{~h}$ (Figure 1C). Western blot of pro-caspases 9 and 7, the DNA damage marker $\mathrm{pH} 2 \mathrm{Ax}$ and cl-PARP also suggested the involvement of the intrinsic apoptotic pathway in $\mathrm{MCF}-7$ cell death (Figure 1D and 1E). These findings provided a time frame for further in vitro experiments. In addition, MCF-7 xenograft mouse models treated with $5 \mathrm{mg} / \mathrm{kg}$ AP for 21 days, displayed a $45 \%$ reduction in tumour weight, while $2 \mathrm{mg} / \mathrm{kg}$ PL treatment exerted no observable effects (Figure 1F). Generally, elevated plasma concentrations of the liver enzyme markers alanine transaminase (ALT), and aspartate transaminase (AST), present in serum or blood, are indicative of stress and toxicity. While PL treatment increased the activity of AST and ALT enzymes in mice serum (Figure $1 \mathrm{G}$ and $1 \mathrm{H}$ ), AP reduced ALT and AST activity by $36 \%$ and $7 \%$ respectively, as compared to vehicle. It is worthwhile mentioning that mice were initially treated with $5 \mathrm{mg} / \mathrm{kg}$ PL however within two days 8 mice succumbed to treatment hence dosage was adjusted to $2 \mathrm{mg} / \mathrm{kg}$. Although in vitro data suggested similar mechanisms of action for PL and AP, which is not unusual as these compounds only differed by a methoxy group, in vivo results suggested otherwise i.e. AP and PL may possess alternate mechanisms since the toxicity of AP in vivo was substantially lower as compared to PL.

\section{Identification of pathways affected by AP and PL}

Next we wanted to elucidate pathways altered by PL and AP in MCF-7 cells to further understand phenotypic differences observed in vivo. MCF-7 cells treated with $10 \mu \mathrm{M}$ PL or AP for $6 \mathrm{~h}$ were subjected to microarray analysis and differentially expressed genes were mapped to biological pathways contained in the IPA (Figure S1). Both PL and AP affected multiple pathways however a clear distinction could be drawn for PL which targeted pathways including ELF2 signalling ( $\mathrm{P}$ $=2.04 \mathrm{E}-08)$, mTOR signalling $(\mathrm{P}=7.57 \mathrm{E}-03)$, and the regulation of elf4 and p70S6K $(\mathrm{P}=2.24 \mathrm{E}-02)$ while AP affected pathways such as hepatic fibrosis $(\mathrm{P}=7.88 \mathrm{E}-$ $05), \mathrm{PXR} / \mathrm{RXR}$ activation $(\mathrm{P}=3.86 \mathrm{E}-03)$, atherosclerosis signalling ( $\mathrm{P}=2.33 \mathrm{E}-02)$, and androgen biosynthesis ( $\mathrm{P}$ $=1.52 \mathrm{E}-02$ ) (Figure S1). Amidst the pathways altered, two distinguishing pathways emerged to which most PL and AP genes were mapped (Figure S2 and S3). For PL, a demarcated mapping of downregulated Complex I, III and IV genes involved in mitochondrial oxidative phosphorylation was noted. Evidence in literature for PL and mitochondrial related processes validate this observation [28-31]. AP altered apolipoprotein genes which mapped well to the atherosclerosis pathway.

\section{Validation of cholesterol depletion mediated cell death induction by AP in MCF-7 cells}

Apolipoproteins are important components of the cholesterol pathway especially in the formation of HDL and LDL cholesterol. Furthermore cholesterol metabolism and $\mathrm{BC}$ aggressiveness and progression are intimately linked as evidenced in numerous studies $[6,7]$. To validate cholesterol alterations suggested by our pathway analysis, we stained lipid rafts and cholesterol with the Vybrant Lipid Raft kit and Filipin respectively in cells treated with $10 \mu \mathrm{M}$ PL or AP (Figure 2A and Figure S4A). The distinct membrane staining of lipid rafts and cholesterol (white arrows) observed in control cells was disrupted in MCF7 cells while BJ cells remained unaffected. Quantitative measurement of cholesterol in BJ, BT20 and MCF-7 cells by AMPLEX Red assay after $2 \mathrm{~h}$ PL and AP treatment revealed a 35\% reduction of cholesterol in MCF-7 cells (Figure 2B). Neither BJ nor BT20 cells were depleted of cholesterol which could explain our previous observation regarding AP selectivity for ER positive BC cells [27]. Additionally cholesterol pre-treatment significantly reduced apoptosis in MCF-7 cells treated with PL (from $30 \%$ to $10 \%$ ) and AP (from $20 \%$ to negligible) (Figure $2 \mathrm{C}$ ), which is similar to observations reported [9].This data suggests that AP induced cholesterol depletion which lead to increased apoptosis in MCF-7 cells. A significantly increased level of CEs and decreased free cholesterol was 
$\mathbf{A}$

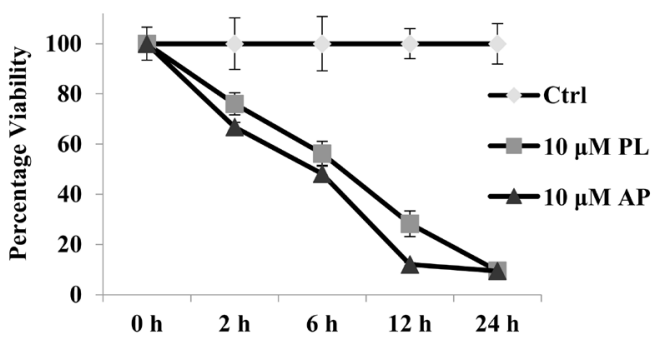

E

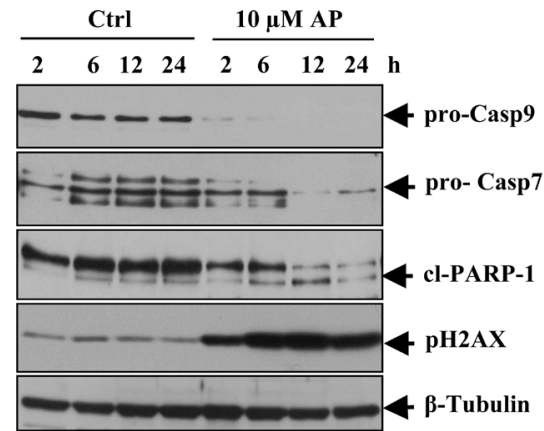

B

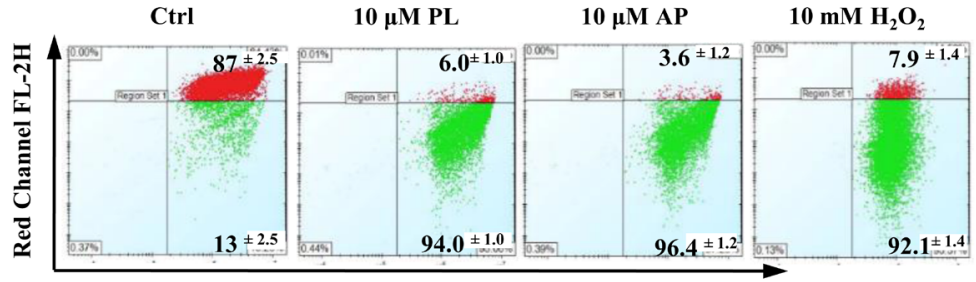

Green Channel FL-1H

C $\square$ Ctrl $\square 10 \mu \mathrm{M}$ PL $\square 10 \mu \mathrm{M}$ AP $\quad$ Positive

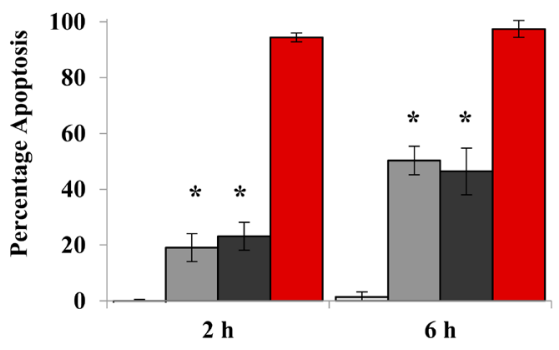

F

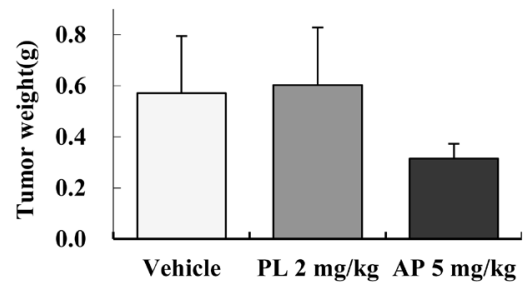

G
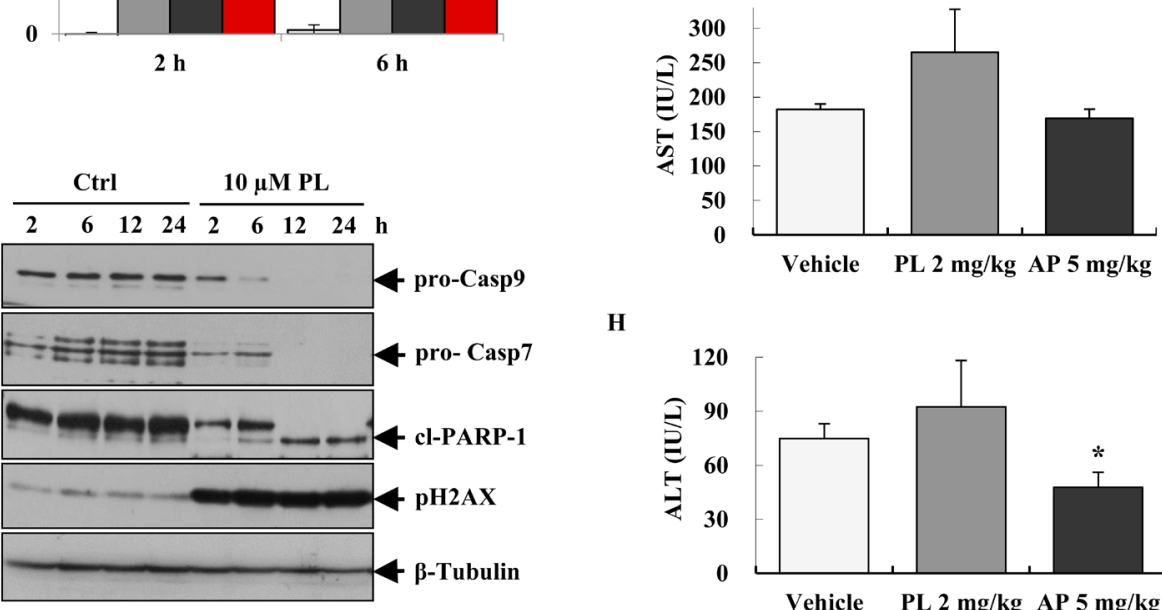

H

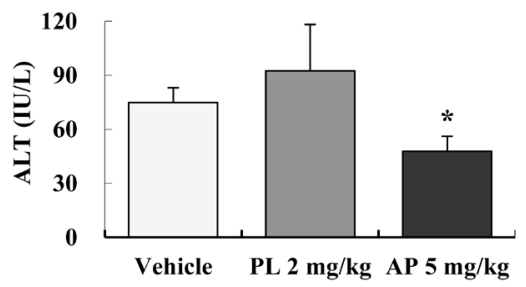

Figure 1: AP induces intrinsic apoptosis in MCF-7 cells and reduces tumour burden in MCF-7 xenograft models. (A) Viability of MCF-7 cells over time after treatment with $10 \mu \mathrm{M}$ PL and AP. (B) MOMP disruption as measured by flow cytometry after treating MCF-7 cells with $10 \mu \mathrm{M}$ PL and AP for $1 \mathrm{~h}$; Ctrl represents cells treated with $0.2 \%$ DMSO. (C) The apoptosis-inducing potential of $10 \mu \mathrm{M}$ PL and AP in MCF-7 as determined by using APOPercentage assay performed at 2 and 6 h. Data shown (in A, B, and $\mathrm{C})$ are representative of mean $\pm \mathrm{SD}$ of quadruplicate wells/condition in at least two independent experiments $(\mathrm{n}=2)$. ${ }^{*}$ Indicates $\mathrm{P}<0.05$ as calculated by students t-test. (D-E) Western blot analysis of pro-Casp9, pro-Casp7, PARP-1 and pH2AX after incubating MCF-7 cells for $2,6,12$, and $24 \mathrm{~h}$ with PL and AP. $\beta$-Tubulin was used as a loading control. Images are representative of three independent experiments $(\mathrm{n}=3)$. (F) The in vivo effect of PL $(2 \mathrm{mg} / \mathrm{kg})$ and AP $(5 \mathrm{mg} / \mathrm{kg})$ on tumour weight and plasma levels of (G) AST and (H) ALT in different groups of MCF-7 xenograft models after 21 days drug treatment. Data shown (in F, G and H) as mean \pm SD of vehicle group ( $\mathrm{n}=4$ ), PLtreated $(n=4)$ and AP-treated $(n=5)$ mice. 
observed in mouse serum in the AP treated group of mice as compared to the vehicle and PL group (Figure 2D). The increase in CEs was in agreement with elevated HDL and LDL levels observed in AP treated mice (Figure S4B). Of more relevance is a physiological balance of total cholesterol/HDL and HDL/LDL ratios as an imbalance correlates with atherosclerosis progression and $\mathrm{BC}$ risk [32]. Total cholesterol/HDL and HDL/LDL ratios measured in vehicle and AP groups were concordant with published data while PL treatment disturbed the HDL/ LDL ratio in the PL group (Table 1).

\section{Identifying role of CETP in cancer survival and response to anticancer agents}

Key proteins involved with regulating cholesterol homeostasis are pertinent to processes including reverse cholesterol transfer (RCT), steroid hormone production and atherosclerosis among others [26, 33]. CETP shuttles CEs and triglycerides between plasma lipoproteins and plays a vital role in reciprocal transfer of these from LDL/ VLDL to HDL. Advanced data mining also connected

B

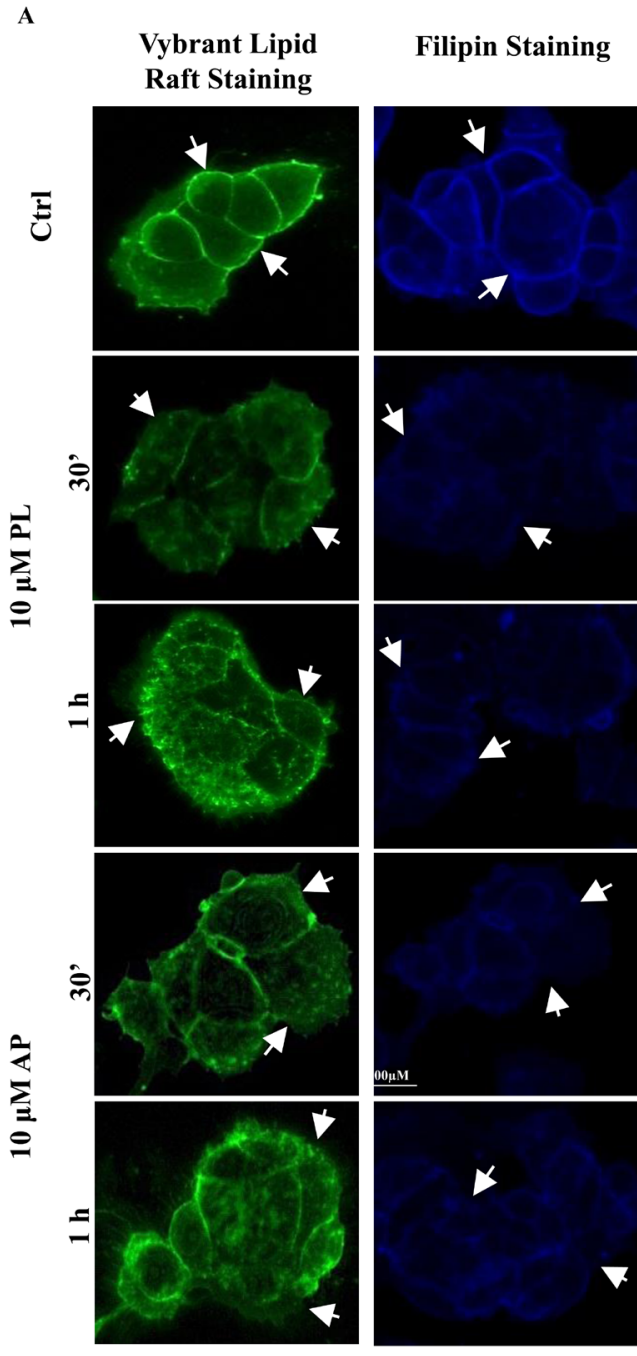

$\mathrm{C}$
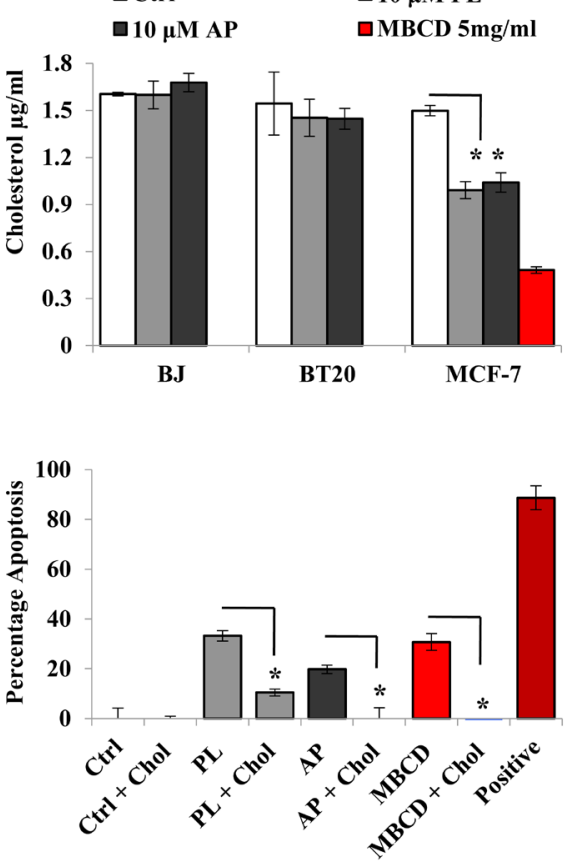

D

口TOTAL Cholesterol aCholesterol Esters

口FREE Cholesterol

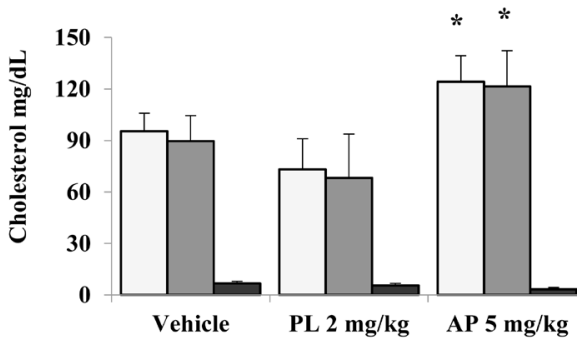

Figure 2: AP disrupts lipid rafts and modulates cholesterol levels in vitro and in vivo. (A) Lipid raft and filipin staining in MCF-7 cells after treatment with $10 \mu \mathrm{M}$ PL or AP for $30 \mathrm{~min}$ and $1 \mathrm{~h}$. Images are representative of three independent experiments (n=3). (B) Comparison of cholesterol depletion in BJ, BT20, and MCF-7 cells after treatment with $10 \mu \mathrm{M}$ PL and AP for $2 \mathrm{~h} ; 5 \mathrm{mg} / \mathrm{ml} \mathrm{MBCD}$ was used as a positive control. (C) Cholesterol pre-incubation blocked apoptosis induction in $10 \mu \mathrm{M}$ PL and AP, and $5 \mathrm{mg} / \mathrm{ml} \mathrm{MBCD}$ treated cells for 2 h. $5 \mathrm{mMH}_{2} \mathrm{O}_{2}$ was used as a positive apoptotic control. Data shown (B and C) are representative of the mean $\pm \mathrm{SD}$ of quadruplicate wells/ condition in at least three independent experiments $(n=3)(P \leq 0.05, t$-test). (D) Levels of total cholesterol, cholesterol esters, and unbound free cholesterol. Data shown as mean \pm SD of vehicle group $(n=4)$, PL treated $(n=4)$ and AP treated $(n=5)$ groups. 
$\mathbf{A}$

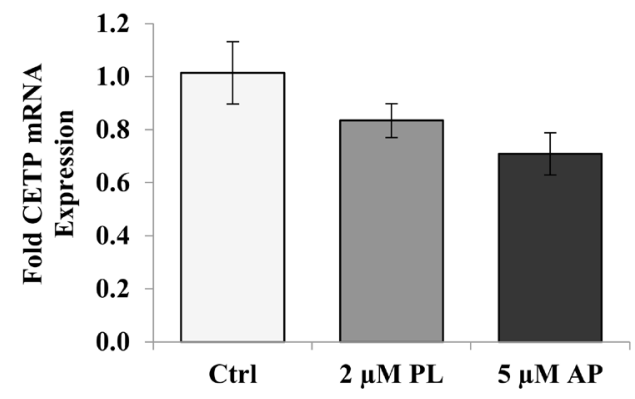

B

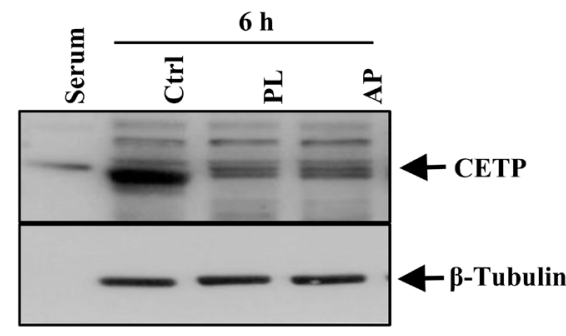

C

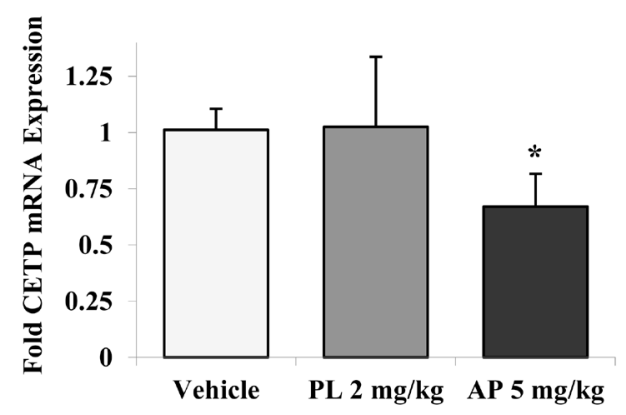

D

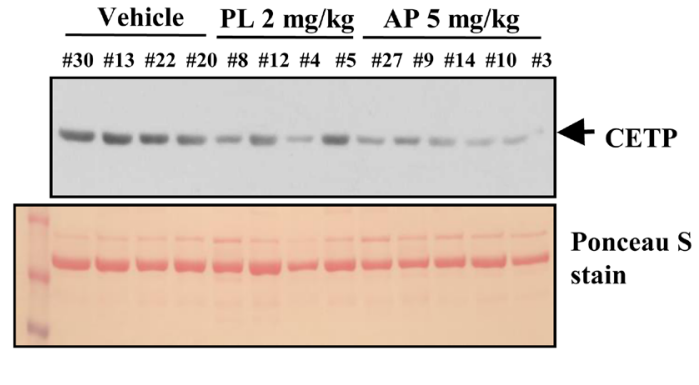

$\mathbf{E}$

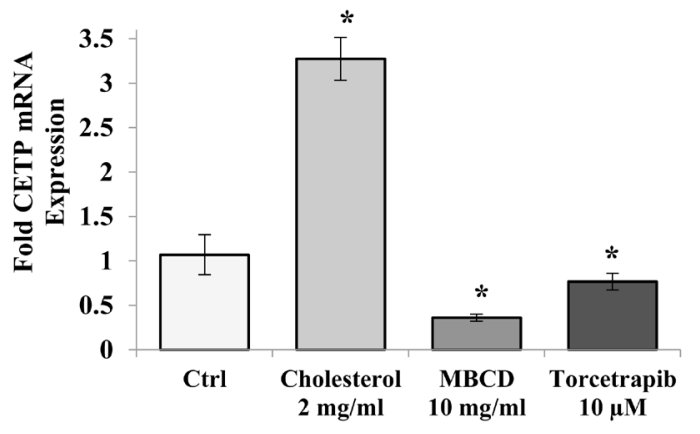

F
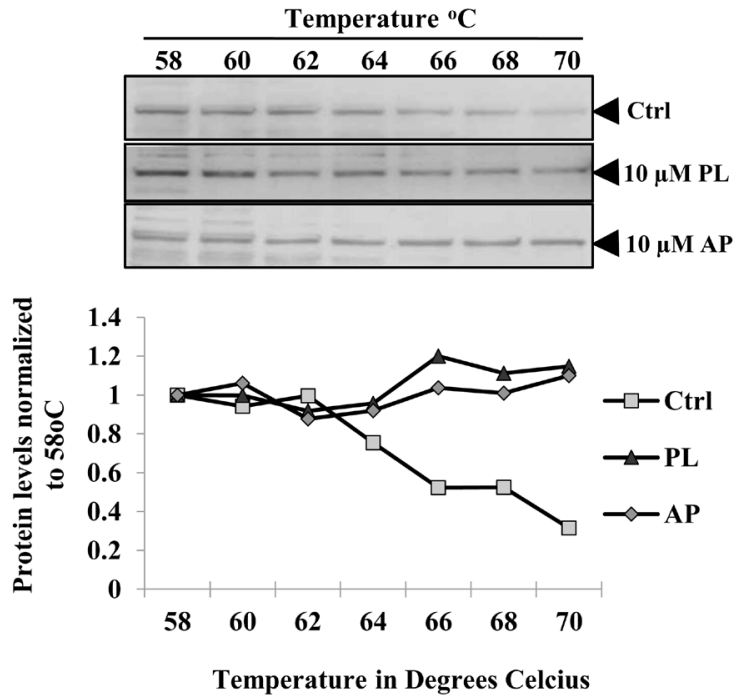

Figure 3: $C E T P$ expression is altered in response to cholesterol modulation. Levels of (A) CETP mRNA in MCF-7 cells treated for 5 days with $2 \mu \mathrm{M}$ PL and $5 \mu \mathrm{M}$ AP and CETP protein levels when treated with $10 \mu \mathrm{M}$ PL and AP for $6 \mathrm{~h}$ (B). CETP mRNA expression in tumour samples (C) and CETP protein levels in mice serum samples (D) after 21 days treatment with PL (2 mg/kg) and AP (5 mg/kg). (E) MCF-7 cells treated with $2 \mathrm{mg} / \mathrm{ml}$ Cholesterol, $10 \mathrm{mg} / \mathrm{ml} \mathrm{MBCD}$ and $10 \mu \mathrm{M}$ Torcetrapib for $48 \mathrm{~h}$. Data shown (C and E) are mean \pm $\mathrm{SD}$ of quadruplicate wells of three independent pooled experiments $(\mathrm{P} \leq 0.05, t$-test $)$. Comparison of CETP protein stability in Ctrl and PL or AP-treated MCF-7 cells during cellular thermal shift analysis. Data shown are representative of three independent experiments (F). 
CETP to the atherosclerosis pathway, which led us to investigate the role of CETP in MCF-7 cells (Figure S5). Treatment with low concentrations of PL and AP for five days' decreased the in vitro expression of CETP mRNA by $15 \%$ and $33 \%$ respectively (Figure $3 \mathrm{~A}$ ). CETP protein level was also reduced after $6 \mathrm{~h}$ treatment with PL and AP (Figure 3B). A significant (35\%) reduction of CETP mRNA was observed in tumour RNA isolated from mice treated for 21 days with AP however PL treatment had no effect (Figure 3C). Furthermore western blot detection revealed reduced CETP serum levels in two out of four PL treated mice and five out of five AP treated mice (Figure $3 \mathrm{D})$. In light of our observations of altered cholesterol metabolism (Figure 2), CETP mRNA and protein levels seem to fluctuate in response to cholesterol levels, which has been reported in literature. In a study by Mark et al [34], CETP levels were upregulated in liposarcoma cells SW872 when incubated with cholesterol. Tissues including hepatocytes and luminal epithelial cells are also known sources of CETP expression however CETP
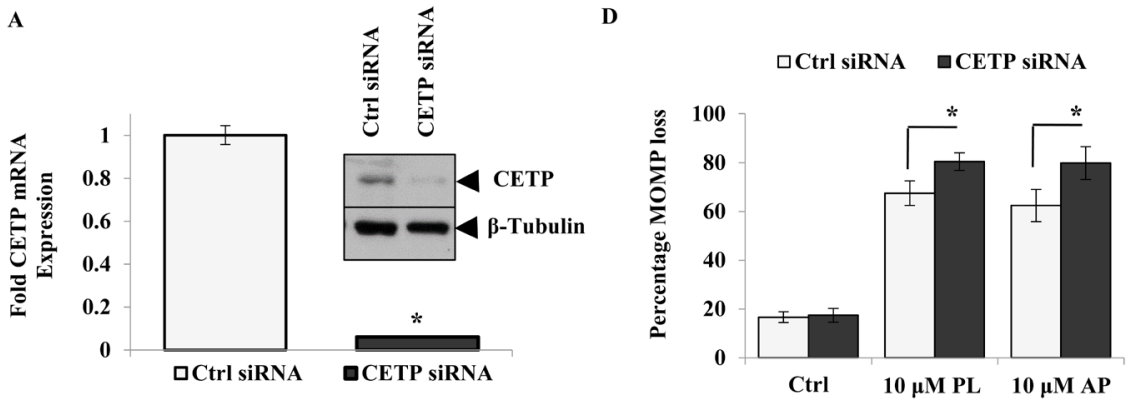

B

$\mathbf{E}$
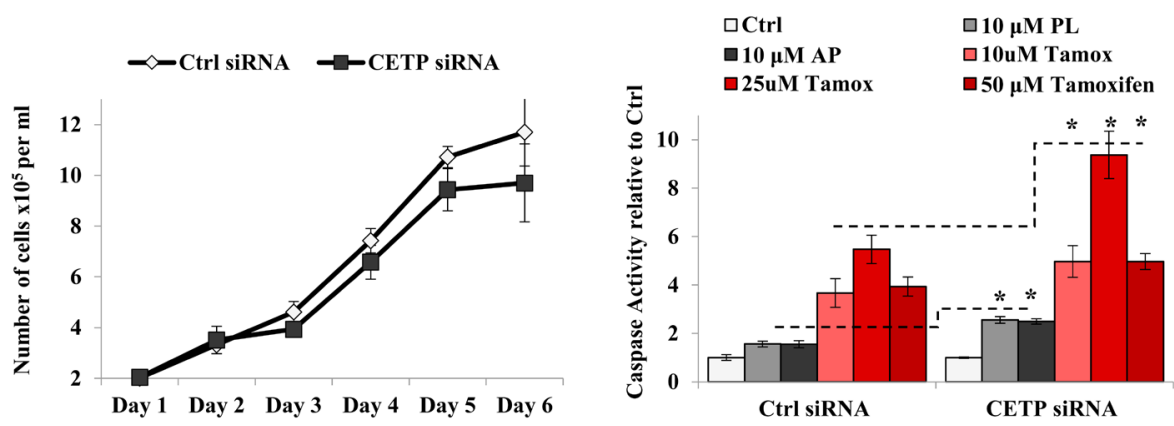

$\mathbf{C}$

F
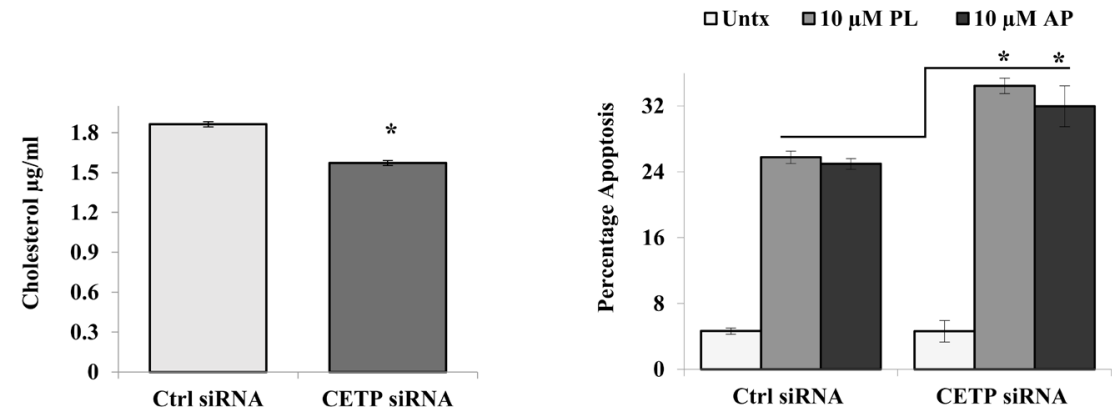

Figure 4: $C E T P$ contributes to cancer cell growth and survival and is upregulated in breast cancer patients. (A) $C E T P$ gene silencing by siRNA and western blot analysis of CETP protein expression in CETP siRNA cells. (B) Effect of CETP mRNA silencing on growth of MCF-7 cells as measured by cell counting over a period of six days. (C) Comparison of cholesterol levels in the MCF-7 control (ctrl) siRNA and CETP knockout cells. Data shown are the mean $\pm \mathrm{SD}$ of quadruplicate wells/condition in three independent experiments $(\mathrm{n}=3)(\mathrm{P} \leq 0.05, t$-test). (D) The effect of $10 \mu \mathrm{M}$ PL or AP treatment on MOMP; (E) Capase-3/7 activity (10, 25 and $50 \mu \mathrm{M}$ Tamoxifen was used as a positive control); and (F) apoptosis in MCF-7 ctrl siRNA and CETP siRNA knockout cells. Data shown are representative of the mean $\pm \mathrm{SD}$ of quadruplicate wells/condition in at least two independent experiments $(\mathrm{n}=2)(* \mathrm{P} \leq 0.05, t$-test $)$. 
A

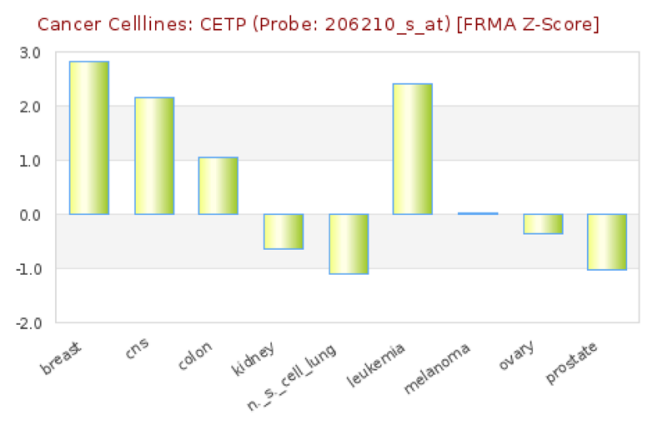

B

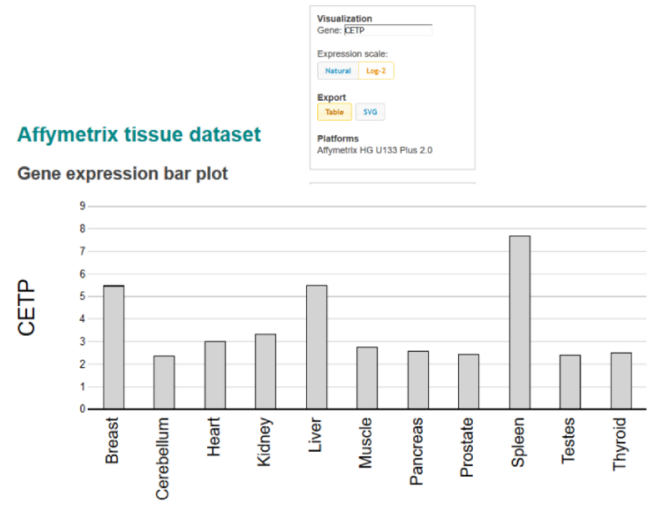

D

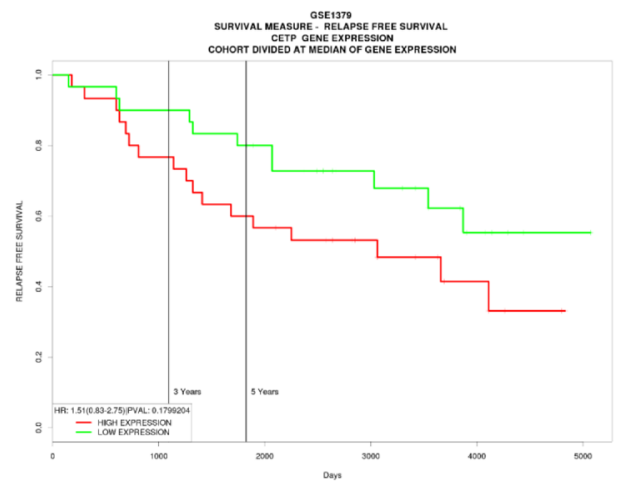

E

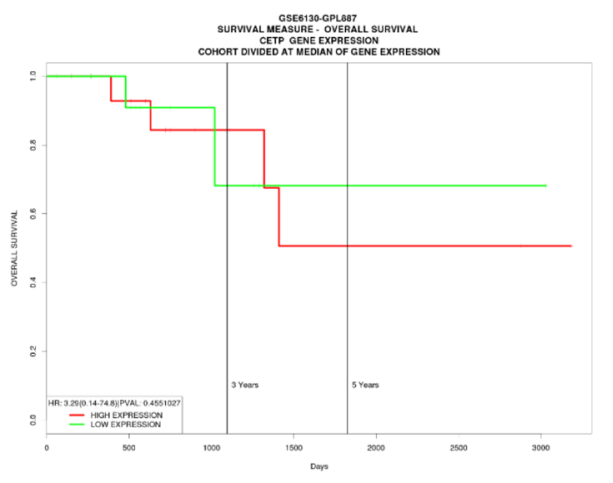

F

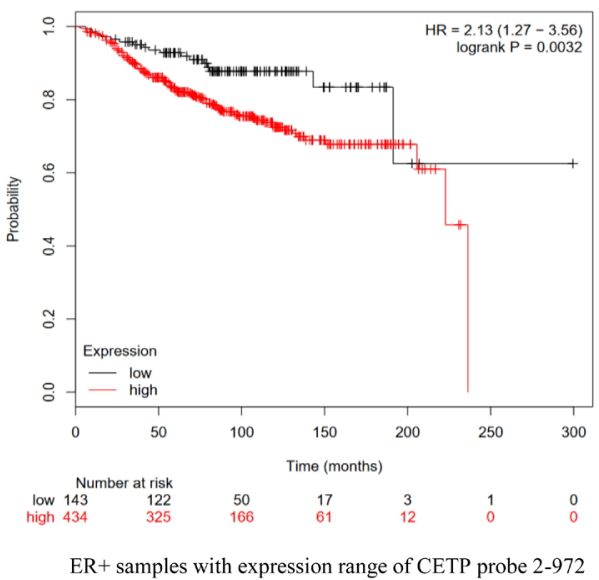

Figure 5: CETP expression analysis in BC cell lines and patients. The expression of CETP in three different databases: (A) the expression of CETP in NCI panel of 60 cell lines (http://medicalgenomics.org/details_view limited? db=cellnavigator\&gene id=1071\&cn option $=\mathrm{m}$ _disease\#v ), (B) the expression of CETP in BC tissue in the Affymetrix tissue dataset (http://www.betastasis.com/tissues/ affymetrix tissue dataset/gene expression barplot affymetrix hg u133 plus 20/ ), and (C) shows expression of CETP in six different $\mathrm{BC}$ patient datasets in the Oncomine database. (D and E) Kaplan-Meier plots of relapse-free survival and overall survival of BC patients stratified by median CETP expression in the Proggene database [48]. (F) the effect of CETP expression level on survival of ER+ and ER$\mathrm{BC}$ patients estimated using KM-Plotter database. Log-rank test $P$-value is displayed on the graphs. 
Table 1: The Ratio of Total Cholesterol/HDL and HDL/LDL in mice

\begin{tabular}{|l|l|l|}
\hline Study Group & Total Cholesterol/HDL & HDL/LDL \\
\hline Reference & 1.38 & 3.0 \\
\hline Vehicle & 1.40 & 3.4 \\
\hline PL $2 \mathrm{mg} / \mathrm{kg}$ & 1.3 & 1.8 \\
\hline AP $5 \mathrm{mg} / \mathrm{kg}$ & 1.4 & 3.1 \\
\hline
\end{tabular}

Ratios of total cholesterol: HDL and HDL: LDL/VLDL in mice serum. Values represent the ratios of means of the vehicle group $(n=4)$, PL-treated $(n=4)$ and AP-treated $(n=5)$ groups.

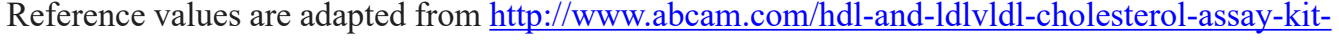
ab65390.html.

expression in response to stimulus has not been reported for BC. MCF-7 cells were incubated with cholesterol, a cholesterol depletory MBCD or the CETP inhibitor Torcetrapib for $48 \mathrm{~h}$ and CETP mRNA levels were determined (Figure 3E). Interestingly, CETP expression was significantly upregulated by cholesterol repletion ( $\geq 3$ fold) while significantly downregulated ( $\leq 2$ fold) by cholesterol depletion or CETP inhibition. Considering that Torcetrapib binds to CETP with high affinity and our observation that it down-regulated CETP expression, we explored by cellular thermal shift assay (CETSA) whether $\mathrm{PL}$ and AP potentially bound to CETP accounting for the decrease in in vitro and in vivo CETP mRNA and protein levels (Figure 3F). Although CETSA is a crude method for measuring protein-drug interactions, we show that $\mathrm{PL}$ and AP were able to substantially increase the thermal stability of CETP compared to control suggesting a potential for CETP-PL/AP interactions.

We next determined the effect of CETP ablation on MCF-7 cell proliferation and survival. Torcetrapib significantly reduced cell growth while not inducing apoptosis at all concentrations tested (Figure S6A and B). Employing a more specific approach using a siRNA cocktail directed to CETP mRNA, CETP gene and protein expression was significantly decreased in MCF-7 cells (Figure 4A). CETP knockdown also decreased cellular growth after 6 days in MCF-7cells (Figure 4B) while only transiently on days 4 and 5 in $\mathrm{BJ}$ cells (Figure S6C).

Cholesterol is important for the synthesis of new membranes in dividing cells and is assimilated into lipid rafts, which provide a scaffold for proliferative receptors (e.g. EGFR) and survival factors (e.g. Akt) [9, 35]. Interestingly, CETP was shown to increase cholesterol uptake in HepG2 cells [36]. To this end, we measured the effect of CETP mitigation on cell cholesterol content and apoptosis in $\mathrm{BC}$ and normal $\mathrm{BJ}$ cells. CETP gene silencing resulted in a significant reduction in cellular cholesterol by $20 \%$ which further antagonized MOMP loss in the presence of PL or AP (Figure 4C and 4D). In conjunction with increased disruption of MOMP, caspase activity and apoptosis were significantly upregulated in CETP siRNA cells compared to Ctrl siRNA cells in response to PL, AP or Tamoxifen treatment (Figure 4E and F). However, BJ cells treated with CETP siRNA were not further sensitized to $\mathrm{PL}$ or AP treatment (Figure S6D). Although not significant, Casp 7 mRNA was also upregulated in CETP knockout cells which possibly contributed to the observed increase in drug sensitivity (Figure S6E).

Thus far our data highlighted key roles of CETP in $\mathrm{BC}$ survival and growth linked to cholesterol metabolic pathways. To assess the relevance of variations in CETP expression, we analysed several online available microarray based $\mathrm{BC}$ databases. We found using the Cell Navigator tool, among several cell lines frequently used by NCI for anticancer drug testing, elevated CETP expression in $\mathrm{BC}$ cell lines (Figure 5A). The expression of CETP was also higher in $\mathrm{BC}$ tissue as compared to other tissues available in the Affymetrix tissue dataset (Figure 5B). Furthermore the expression analysis showed significantly elevated CETP expression in $\mathrm{BC}$ vs normal patients in six previously published datasets contained in Oncomine (Figure 5C). Correlation of CETP expression with $B C$ patient survival using four different $B C$ datasets revealed that patients expressing low levels of CETP have longer relapse free survival and improved overall survival (Figure 5D and E). Lastly we found, using the online KMPlotter database [37], that ER+ BC patients express higher levels of CETP and have a significantly lower probability of long-term survival (P-value $<0.0032$ ) as compared to ER-patients (Figure 5F). While compiling our results an indirect evidence for involvement of CETP in the aetiology of $\mathrm{BC}$ in African American women came from a study base on gene-based and single-SNP analyses [38].

\section{DISCUSSION}

The advent of linking cholesterol, cholesterol metabolites and cholesterol modulators with $\mathrm{BC}$ is changing the view for future $\mathrm{BC}$ management and treatment. Altogether a better understanding of cholesterol processes in $\mathrm{ER}+\mathrm{BC}$ is being unravelled in light of failed clinical response to selective ER modulators (SERMs) like Tamoxifen and aromatase inhibitors. Recently Shim et al. found that endothelial and $\mathrm{BC}$ cell proliferation was inhibited in a cholesterol-dependent manner, unrelated to ER inhibition, by high concentrations of Tamoxifen [39]. Notably continued activation of ER signalling despite aromatase therapy or tamoxifen treatment has 
been attributed to non-aromatized molecules like 27 hydroxycholesterol $(27 \mathrm{HC})$ and 25 hydroxycholesterol $(25 \mathrm{HC})$. Wu et al. reported that $\mathrm{ER}+\mathrm{BC}$ cell growth was augmented both in vitro and in vivo by $27 \mathrm{HC}$ [16]. Furthermore the abundance of $27 \mathrm{HC}$ was found elevated in normal breast tissue and in the adjacent cancer site of BC patients [16]. Likewise, 25HC stimulated MCF7 and BG-1 cell growth via the $\mathrm{ER} \alpha$ in vitro and $25 \mathrm{HC}$ plasma levels were increased after a high cholesterol meal in vivo [40]. Interestingly the expression of oxysterol $7 \alpha$-hydroxylase (CYP7B1), an enzyme which catabolises both $27 \mathrm{HC}$ and $25 \mathrm{HC}$, is decreased in $\mathrm{ER}+\mathrm{BC}$ patient tissue and is predictive of overall poor survival [16, 40]. The cholesterol pathway constituents like LDL cholesterol, cholesterol receptors LDLR and SCARB1 and others have strong correlation with $\mathrm{BC}$ progression and clinical outcome [15, 21, 41-44]. These emerging data undeniably highlights the requirement for cholesterol modulating agents in $\mathrm{BC}$ management.

Although PL has been well studied for over 40 years, its failure in clinical testing due to toxicity may have impeded the discovery of PL derivatives, such as AP, as anticancer lead molecules. In our current study we provide intriguing evidence identifying CETP as a potential molecular target in ER+ BC. We found that AP induced apoptosis in vitro and was able to reduce tumour growth in vivo with no associated toxicity. Gene expression analysis was further able to delineate ROS and atherosclerosis pathways targeted by PL and AP respectively previewing their mechanisms of action. We further confirmed, as predicted by pathway analysis, that AP is a cholesterol depletor as evidenced by in vitro and in vivo findings. Despite PL displaying similar in vitro characteristics to AP, its dissonance with in vivo mechanisms may be explained by its characteristic ROS inducing properties. ROS accumulation potently oxidizes proteins, lipids and causes DNA damage which we observed previously and in this study [27]. Furthermore HDL, being one of the key transporters of hydroperoxides to hepatocytes, is more prone to lipid peroxidation during major disruptions in the redox status. An in vivo study by Sukkasem et al. is one of few studies reporting an imbalance in the antioxidative system and hepatotoxic effects of PL in mice [37]. Similar to this study, we also observed an increase in the liver damage markers ALT and AST in mice plasma and substantial alterations of the HDL/LDL ratio in the PL treated mice group all of which may have been due to PL induced ROS build-up. AP on the other hand significantly increased cholesterol and HDL/LDL levels in serum without disturbing the HDL/LDL ratio suggesting increased cholesterol efflux. Although AP is capable of producing ROS, its unique mechanism of action as determined by pathway analysis and in vivo phenotype suggests a distinct interactome. In retrospect these factors may underpin the in vivo differences seen for AP and PL.

The highlight of our findings is that AP, decreased
CETP gene expression and protein levels in vitro and in MCF-7 BC xenografts. For the first time, we also show alteration of CETP gene expression in MCF-7 cells in response to: Torcetrapib treatment; to addition or depletion of cholesterol and binding of CETP to AP by CETSA which may provide insights into the regulation of CETP. Importantly we show that CETP contributes to $\mathrm{MCF}-7$ proliferation, cholesterol uptake and survival as silencing CETP reduced cell numbers, cholesterol content and sensitized cells to apoptosis. Our analysis of CETP expression in several databases across cell line, $\mathrm{BC}$ tissue and patient gene expression data also provides evidence for the implication of CETP in $\mathrm{BC}$ as it was found commonly overexpressed in $\mathrm{BC}$ cases, correlated with poor relapse free and overall survival and a significant probability of poor long-term survival for ER+ $\mathrm{BC}$ patients. These observations may be crucial in light of the evidence that CETP: is elevated in $\mathrm{BC}$; increases cholesterol uptake in $\mathrm{BC}$ cells; mediates the transfer of free cholesterol between lipoproteins and membranes; shuttles estradiol (E2) between HDL and LDL; and augments estradiol delivery to tissues, potentially enhancing estrogen signalling [24]. Furthermore, AP significantly decreased estrogen receptor- 1 (ESR-1) and elevated the CETP inhibitor APOF gene expression which further adds another level of regulation mediated by the therapeutic small molecule (AP) in the CETP pathway (Figure S6F and G). AP may have potential as an anticancer drug and anti-atherosclerosis agent. The present study lacks testing of CETP knock-out on cholesterol processing and storing capacity of the $\mathrm{BC}$ cells, and also molecular effects of CETP knock-out on HDL/LDL sizes and expression of various receptors involved in the cholesterol pathway. Nevertheless, our findings provide evidence for a previously unknown role of CETP in ER+ $\mathrm{BC}$ which may present a pharmacologically important and unexploited cellular target in BC. Further in-depth investigation of CETP's contribution in developing and sustaining $\mathrm{BC}$ growth is warranted.

\section{MATERIALS AND METHODS}

\section{Materials}

Dulbecco's Modified Eagle Medium (DMEM), fetal calf serum (FCS), penicillin-streptomycin, Trizol, propidium iodide (PI), and TaqMan Universal Master Mix were obtained from Life Technologies, UK. Tamoxifen, paclitaxel, methyl-beta-cyclodextrin (MBCD), hydrogen peroxide $\left(\mathrm{H}_{2} \mathrm{O}_{2}\right)$, cholesterol, 5-fluorouracil, $\mathrm{PL}$, and MTT (3-(4,5-Dimethylthiazol-z-yl)-2,5-diphenyltetrazolium bromide) were purchased from Sigma Chemicals, USA. AP was synthesized as previously described [27]. 


\section{Cell Culture}

Authenticated by STR profiling and mycoplasmafree MCF-7 (human breast adenocarcinoma; $\mathrm{ATCC}^{\mathrm{B}}$ HTB-22 ${ }^{\mathrm{TM}}$ ), BT20 (human breast carcinoma; $\mathrm{ATCC}^{\circledR}$ HTB- $19^{\mathrm{TM}}$ ), and BJ cells (normal skin fibroblasts; $\mathrm{ATCC}^{\circledR}$ CRL-2522 ${ }^{\mathrm{TM}}$ ) were procured from the American Type Cell Culture Collection (ATCC, Manassas, VA). Cells were cultured in DMEM supplemented with $10 \%$ FCS, penicillin $(100 \mathrm{U} / \mathrm{ml})$, and streptomycin $(100 \mu \mathrm{g} / \mathrm{ml})$ (Gibco) at $5 \% \mathrm{CO}_{2}$ in a $37^{\circ} \mathrm{C}$ incubator.

\section{Growth inhibition assay}

The effect of PL and AP on cell viability was estimated by using the MTT assay as previously described [27], control cells were treated with relevant concentrations of solvent only (maximum $0.2 \%$ DMSO). Optical Density was measured at $595 \mathrm{~nm}$ using a microtiter plate reader (BMG Labtech PHERAstar FS, Germany), and the percentage viability was determined using Microsoft Office Excel $\mathbb{C}$.

\section{APOPercentage Assay}

MCF-7 cells seeded in 96-well plates were treated with $0.2 \%$ DMSO (control), PL and AP compounds for the times described previously [27]. Cells were detached and stained with APOPercentage dye (Biocolor, UK) as described in [45], and apoptotic cells were quantified with a high throughput flow cytometer (HTFC) screening system (IntelliCyt Corporation, Albuquerque, NM).

\section{Mitochondrial Outer Membrane Potential (MOMP) assay}

MCF-7 cells cultured in 96-well plates were stained with $2 \mu \mathrm{M}$ cyanine dye JC-1 (5,5',6,6'-tetrachloro-1,1',3,3'tetraethylbenzimi- dazolylcarbocyanine iodide) (Life Technologies, UK) for 1 has described [45]. 10 $\mathrm{mM} \mathrm{H}_{2} \mathrm{O}_{2}$ was used as a positive control and cells were analysed by the HTFC system by plotting FL2-H vs. FL-1H and applying a quadrant gate to determine JC-1 aggregates (red) and monomers (green).

\section{RNA isolation and cDNA synthesis}

As previously described [27], total RNA isolated from MCF-7 cells was converted to cDNA and stored at $-20^{\circ} \mathrm{C}$. The tumour tissue samples frozen in liquid nitrogen were placed into cold tubes in a MasterPrepTM24 (Hichuang Co.) and homogenized. Trizol (1 ml/50-100 mg tissue) was added to the tissues, and homogenized samples were kept on ice. After homogenization, the samples were incubated at room temperature for $5 \mathrm{~min}$, $200 \mu \mathrm{l}$ of chloroform was added to each sample, and sample was vigorously shook by hand for 15 seconds and incubated at room temperature for 2-3 minutes ( $\mathrm{min}$ ). Samples were centrifuged at $12,000 \mathrm{x}$ g for $15 \mathrm{~min}$ at $4^{\circ} \mathrm{C}$, and the aqueous phase was transferred to a new 1.5 $\mathrm{ml}$ microcentrifuge tube. Next, $0.5 \mathrm{ml}$ of isopropanol was added to the aqueous phase, incubated at room temperature for $10 \mathrm{~min}$, and centrifuged at $12,000 \times \mathrm{g}$ for $10 \mathrm{~min}$ at $4^{\circ} \mathrm{C}$. The supernatant was removed, leaving only the RNA pellet. $1 \mathrm{ml} \mathrm{75 \%}$ ethanol was added to the pellet and the tube was centrifuged at $7500 \times \mathrm{g}$ for $5 \mathrm{~min}$ at $4^{\circ} \mathrm{C}$. After pouring off the supernatant, the RNA pellet was resuspended in $30 \mu \mathrm{l}$ of RNase-free water, and was stored at $-80^{\circ} \mathrm{C}$.

\section{Gene Expression using qRT-PCR}

Quantitative gene expression for CETP (Applied Biosystems TaqMan Assay No. s2934) was performed on a StepOnePlus ${ }^{\mathrm{TM}}$ Real-Time PCR machine (Applied Biosystems) using the TaqMan Universal Master Mix (Applied Biosystems). GAPDH was used as a housekeeping gene and fold gene expression was calculated using the $2^{-\Delta \Delta C \mathrm{~T}}$ method.

\section{siRNA transfection}

$6 \times 10^{5}$ cells were transfected with $40 \mathrm{nmolCETP}$ siRNA (Applied Biosystems) or Control siRNA (Eurofins) using the FuGene HD (Promega) reagent as per the manufacturer's instructions. Briefly, cells were trypsinized with $2 \mathrm{ml}$ of trypsin, and $4 \mathrm{ml}$ of complete media was added to deactivate the trypsin. Cell numbers were determined and $6 \times 10^{5}$ cells were aliquoted into 2 $\mathrm{ml}$ of media. The transfection cocktail containing $30 \mu \mathrm{l}$ of the FuGene HD and either $4 \mu 1$ of the control or CETP siRNA $(40 \mathrm{nmol})$ in $500 \mu \mathrm{l}$ of serum-free media was added dropwise to cells. Cells were cultured in 6- or 96well plates for $72 \mathrm{~h}$ before further analysis was performed.

\section{Caspase-3/7 activity}

Cells were seeded at a density of $2.5 \times 10^{3}$ cells per well in $20 \mu \mathrm{l}$ of media in 384-well plates and treated with PL and AP for the desired time. Caspase-3/7 activity was determined with the ApoTox-Glo kit (Promega) according to the manufacturer's instructions, and luminescence was measured using a plate reader (BMG Labtech PHERAstar $F S$, Germany). 


\section{Lipid-Raft Staining}

Cells grown in 6-well plates to $50-60 \%$ confluency were stained with the Vybrant ${ }^{\circledR}$ Alexa Fluor ${ }^{\circledR} 594$ Lipid Raft Labeling Kit (Life Technologies) and Alexa Fluor ${ }^{\circledR}$ 594 Phalloidin (Life Technologies) according to the manufacturer's instructions. Images were captured with a Floid ${ }^{\circledR}$ Cell Imaging Station (Life Technologies).

\section{Cholesterol Assays}

Cells plated at a density of $5 \times 10^{3}$ per well in a 96well plate for $24 \mathrm{~h}$ were treated with AP/PL as indicated in the Figures. For cholesterol rescue experiments, cells were pretreated with $1 \mathrm{mM}$ cholesterol (chloroform soluble) for $1 \mathrm{~h}$ followed by AP/PL treatment for apoptosis or with $2 \mathrm{mg} / \mathrm{ml}$ water soluble cholesterol for $48 \mathrm{~h}$ for CETP gene expression. Total cholesterol, HDL, and VLDL/ LDL levels were determined using the HDL and LDL/ VLDL Quantification Colorimetric/Fluorometric Kit from BioVision following the manufacturer's recommendations. Free cholesterol and cholesterol esters were measured using the Amplex ${ }^{\circledR}$ Red Cholesterol Assay Kit (Life Technologies) as per the manufacturer's instructions.

\section{Microarray and pathway identification}

RNA was extracted as per the method previously described [27] and was quantified and quality checked using a nanodrop-ND 8000 spectrophotometer (Thermo Fisher Scientific, San Jose, CA, USA) and the 2100 Bioanalyzer (Agilent Technologies, Santa Clara, CA, USA), respectively. Samples with an RNA integrity number (RIN) of nine and above were chosen for microarray analysis, which was performed using the Human Gene Expression 4x44K v2 Microarray Kit, Design ID: 026652 (Agilent Technologies) containing 45220 features and 1377 Agilent control probes. The signal intensities were extracted from the scanned images with the Feature Extraction Software 10.7.1.1 (Agilent Technologies) and were subjected to background subtraction and spatial detrending. The outliers and the abnormal features were flagged, and the data was normalized using the intra-array percentile shift normalization (threshold of 75 and above) and medianbased inter-array normalization. The GeneSpring GX (Agilent Technologies) was used to calculate the intensity ratios and fold changes. All the genes with a $\mathrm{P}<0.05$ and a fold change of 2 were chosen for pathway analysis. The pathways were generated through the use of QIAGEN's Ingenuity Pathway Analysis (IPA ${ }^{\circledR}$, QIAGEN Redwood City, www.qiagen.com/ingenuity). Microarray data has been made publicly available in GEO (no: GSE68026).

\section{Xenograft study}

The nonblinded study was performed by GenScript (http://www.genscript.com) with approvals of study protocols and animal use under IACUC No: 07X02015312.01. Initially ten mice per study group were randomly selected but eight mice succumbed to treatment due to toxicity within four to six days when treated with $5 \mathrm{mg} / \mathrm{kg}$ PL; hence the well-tolerated PL dose of $2 \mathrm{mg} / \mathrm{kg}$ was used (data not shown). We included four more mice in the PL treatment study. Body weight was used as an exclusion criterion to balance the number of mice in each group. Later, one mouse in the vehicle and two mice in PL-treated group also died.

$\mathrm{BALB} / \mathrm{c}$ female nude mice were used for the study. MCF-7 cells $\left(1.0 \times 10^{7}\right)$ in $0.1 \mathrm{ml}$ of PBS plus matrigel (1:1) /mouse were implanted, when tumours reached 300-500 $\mathrm{mm}^{3}$, the tumour mass was harvested, cut into $1-2 \mathrm{~mm}^{3}$ pieces, and then surgically implanted into the study group. Before the study began, tumours were allowed to reach $150-200 \mathrm{~mm}^{3}$. The mice were divided randomly into three groups: vehicle ( $\mathrm{n}=4,25 \%$ PEG400, 200 $\mu 1 / 20 \mathrm{~g}$ mouse, i.p., q.d.), AP treated ( $\mathrm{n}=5,5 \mathrm{mg} / \mathrm{kg}$, i.p, qd), and PL treated ( $\mathrm{n}=4,2 \mathrm{mg} / \mathrm{kg}$, i.p., q.d.), and treated for 21 days. At the end of the experiment the mice were necropsied; blood was collected for aspartate aminotransferase (AST) and alanine aminotransferase (ALT) measurements. Tumour volume and body weight were measured every second day. Tumour size was expressed in $\mathrm{mm}^{3}$ using the formula $\mathrm{V}=1 / 2 \times a \times b^{2}$, where ' $a$ ' and ' $b$ ' represent the long and short diameters of the tumour, respectively. The tumour mass was weighed, photographed after harvest and snap frozen in liquid nitrogen for RNA extraction. Tumour inhibition rate was calculated as inhibition rate $(\%)=($ average tumour volume of control group-average tumour volume of test group)/ average tumour volume of control group $\times 100 \%$.

\section{Cellular Thermal Shift Assay (CETSA)}

The protein-drug binding thermal shift assay was employed to test the binding of PL/AP to CETP [46]. Briefly MCF-7 cells grown to $60 \%$ confluency in T75 flasks were treated with PL, AP or Torcetrapib for $2 \mathrm{~h}$ at $37^{\circ} \mathrm{C}$. Cells were trypsinized, counted, and washed twice with $1 \mathrm{x}$ PBS. The cell pellet was resuspended in 1 $x$ EDTA-free protease inhibitors and aliquoted into PCR tubes at $1.5 \times 10^{6}$ cells per tube. Tubes were placed in a Veriti ${ }^{\circledR}$ 96-Well Thermal Cycler (Applied Biosystems) and incubated for $3 \mathrm{~min}$ at $56-74^{\circ} \mathrm{C}$ with $2^{\circ} \mathrm{C}$ increments. Tubes were taken out of the thermal cycler and incubated at room temperature for $3 \mathrm{~min}$. Cells were lysed by freezethawing the tubes twice in liquid nitrogen and at $25^{\circ} \mathrm{C}$ for 3 min with vortexing in between freeze-thaw cycles. Immediately after, cells were centrifuged at $14000 \mathrm{rpm}$ 
and $4^{\circ} \mathrm{C}$ for $20 \mathrm{~min}$, and the supernatant was transferred to a clean Eppendorf tube. Protein was quantified using the BCA protein determination kit (Pierce Thermo Scientific, USA), and equal amounts of protein (15-20 $\mu \mathrm{g})$ were subjected to Western blotting for CETP detection.

\section{Western Blotting}

Protein lysate harvested from MCF-7 cells was quantitated with the BCA protein determination kit (Pierce Thermo Scientific, USA). An equal amount (20-30 $\mu \mathrm{g})$ of protein lysate was subjected to gel electrophoresis on $10 \%$ SDS page gels, transferred to nitrocellulose membrane and probed with antibodies to PARP-1 (C210,Trevigen, diluted 1:1000), Pro-Caspase-7 (PRS3467, Sigma, diluted 1:1000), Pro-Caspase-9 (MA1-12562, Thermo Scientific, diluted 1:1000), pH2AX (ADI-KAMCC255, Enzo Life Sciences, diluted 1:4000), and CETP (PA1-050, ABR, diluted 1:500). $\beta$-Tubulin (sc-9104, Santa Cruz Biotechnology, diluted 1:1000) was used as a loading control. Fold change in expression of the serum protein was determined using densitometry analysis of Western blots using ImageJ.

\section{Statistical analysis}

A Z-factor of $\geq 0.6$ was recorded for each assay, indicating good to excellent robustness [47]. A student's $t$-test was used to determine statistical significance where $\mathrm{p}<0.05$ or $\mathrm{p}<0.005$. All statistics including mean and standard deviation (SD) calculations were performed using Microsoft Office ExcelC. A normal distribution of data was assumed for statistical analyses. SD was calculated to estimate variation within each group of data and the range of SD was typically similar between groups. Experiments were performed in 96- and 384-well plates in duplicate/ triplicate as indicated in the Figure legends and each experiment further included triplicate or quadruplicate wells for each condition.

\section{Abbreviations}

$25 \mathrm{HC}-25$ Hydroxy-cholesterol

27HC - 27 Hydroxy-cholesterol

ALT - alanine aminotransferase

AP - Acetyl Plumbagin

AST - aspartate aminotransferase

$\mathrm{BC}$ - Breast cancer

CE - Cholesteryl ester

CETP - Cholesteryl ester transfer protein (protein)

CETP - Cholesteryl ester transfer protein (mRNA)

CYP7B1 - oxysterol 7 $\alpha$-hydroxylase

DMEM - Dulbecco's Modified Eagle Medium

ER - Estrogen receptor
FCS - Fetal calf serum

HDL - High density lipoprotein

HTFC - High throughput flow cytometer

$\mathrm{H}_{2} \mathrm{O}_{2}-$ Hydrogen peroxide

i.p. - Intraperitoneal

IPA - Ingenuity Pathway Analysis

JC-1 - (5,5',6,6'-tetrachloro-1,1',3,3'-tetra ethyl

benzimi- dazolylcarbocyanine iodide)

LDL - Low density lipoprotein

MBCD - Methyl-beta-cyclodextrin

MTT - (3-(4,5-Dimethylthiazol-z-yl)-2,5-diphenyl

tetrazolium bromide)

NCI - National cancer institute

PBS - phosphate buffered saline

PI - Propidium Iodide

$\mathrm{PL}$ - Plumbagin

RCT - Reverse Cholesterol Transfer

RNA - Ribonucleic Acid

ROS - Reactive Oxygen Species

SD - Standard Deviation

siRNA - Small Interfering RNA

SR-B1 - Scavenger receptor class B, Member 1

STR - Short Tandem Repeat

CETSA - Cellular Thermal Shift Assay

q.d.- quaque die

VLDL - Very Low Density Lipoprotein

\section{ACKNOWLEDGEMENTS}

Authors would like to acknowledge the funding support from King Abdullah University of Science and Technology, Thuwal, Saudi Arabia.

\section{CONFLICT OF INTEREST}

Authors LE, SS and MK have filed a patent (application no: PCT/IB 2016/050987), although this is not commercialized. DB declares on competing interests.

\section{GRANT SUPPORT}

This research did not receive any specific grant from funding agencies in the public, commercial, or not-forprofit sector.

\section{Statement on the welfare of animals}

The mice study was performed by GenScript (http:// www.genscript.com) with approvals of study protocols and animal use under IACUC No: 07X02015312.01.

\section{REFERENCES}

1. Silvente-Poirot S and Poirot M. Cholesterol metabolism and cancer: the good, the bad and the ugly. Current opinion in 
pharmacology. 2012; 12(6):673-676.

2. Furberg AS, Jasienska G, Bjurstam N, Torjesen PA, Emaus A, Lipson SF, Ellison PT and Thune I. Metabolic and hormonal profiles: HDL cholesterol as a plausible biomarker of breast cancer risk. The Norwegian EBBA Study. Cancer epidemiology, biomarkers \& prevention: a publication of the American Association for Cancer Research, cosponsored by the American Society of Preventive Oncology. 2005; 14(1):33-40.

3. Liu YL, Qian HX, Qin L, Zhou XJ and Zhang B. Serum LDL-C and LDL-C/HDL-C ratio are positively correlated to lymph node stages in males with colorectal cancer. Hepato-gastroenterology. 2011; 58(106):383-387.

4. Vilchez JA, Martinez-Ruiz A, Sancho-Rodriguez N, Martinez-Hernandez P and Noguera-Velasco JA. The real role of prediagnostic high-density lipoprotein cholesterol and the cancer risk: a concise review. European journal of clinical investigation. 2014; 44(1):103-114.

5. Clendening JW and Penn LZ. Targeting tumor cell metabolism with statins. Oncogene. 2012; 31(48):49674978.

6. Ginestier C, Monville F, Wicinski J, Cabaud O, Cervera N, Josselin E, Finetti P, Guille A, Larderet G, Viens P, Sebti S, Bertucci F, Birnbaum D and Charafe-Jauffret E. Mevalonate metabolism regulates Basal breast cancer stem cells and is a potential therapeutic target. Stem cells (Dayton, Ohio). 2012; 30(7):1327-1337.

7. Mo H and Elson CE. Studies of the isoprenoid-mediated inhibition of mevalonate synthesis applied to cancer chemotherapy and chemoprevention. Experimental biology and medicine (Maywood, NJ). 2004; 229(7):567-585.

8. Babina IS, Donatello S, Nabi IR and Hopkins AM. Lipid rafts as master regulators of breast cancer cell function. 2011.

9. Li YC, Park MJ, Ye SK, Kim CW and Kim YN. Elevated levels of cholesterol-rich lipid rafts in cancer cells are correlated with apoptosis sensitivity induced by cholesteroldepleting agents. The American journal of pathology. 2006; 168(4):1107-1118; quiz 1404-1105.

10. Dillard PR, Lin MF and Khan SA. Androgen-independent prostate cancer cells acquire the complete steroidogenic potential of synthesizing testosterone from cholesterol. Molecular and cellular endocrinology. 2008; 295(1-2):115120.

11. Mostaghel EA, Solomon KR, Pelton K, Freeman MR and Montgomery RB. Impact of circulating cholesterol levels on growth and intratumoral androgen concentration of prostate tumors. PloS one. 2012; 7(1):e30062.

12. Gorin A, Gabitova L and Astsaturov I. Regulation of cholesterol biosynthesis and cancer signaling. Current opinion in pharmacology. 2012; 12(6):710-716.

13. Llaverias G, Danilo C, Mercier I, Daumer K, Capozza F, Williams TM, Sotgia F, Lisanti MP and Frank PG. Role of cholesterol in the development and progression of breast cancer. The American journal of pathology. 2011;
178(1):402-412.

14. Nelson ER, Chang CY and McDonnell DP. Cholesterol and breast cancer pathophysiology. Trends in endocrinology and metabolism: TEM. 2014; 25(12):649-655.

15. Nelson ER, Wardell SE, Jasper JS, Park S, Suchindran S, Howe MK, Carver NJ, Pillai RV, Sullivan PM, Sondhi V, Umetani M, Geradts J and McDonnell DP. 27-Hydroxycholesterol links hypercholesterolemia and breast cancer pathophysiology. Science (New York, NY). 2013; 342(6162):1094-1098.

16. Wu Q, Ishikawa $\mathrm{T}$, Sirianni R, Tang H, McDonald JG, Yuhanna IS, Thompson B, Girard L, Mineo C, Brekken RA, Umetani M, Euhus DM, Xie Y and Shaul PW. 27-Hydroxycholesterol promotes cell-autonomous, ERpositive breast cancer growth. Cell reports. 2013; 5(3):637645.

17. Mohammad N, Malvi P, Meena AS, Singh SV, Chaube B, Vannuruswamy G, Kulkarni MJ and Bhat MK. Cholesterol depletion by methyl-beta-cyclodextrin augments tamoxifen induced cell death by enhancing its uptake in melanoma. Molecular cancer. 2014; 13:204.

18. Silvente-Poirot $\mathrm{S}$ and Poirot M. Cholesterol and Cancer, in the Balance. Science (New York, NY). 2014; 343(6178):1445-1446.

19. Warita K, Warita T, Beckwitt CH, Schurdak ME, Vazquez A, Wells A and Oltvai ZN. Statin-induced mevalonate pathway inhibition attenuates the growth of mesenchymallike cancer cells that lack functional E-cadherin mediated cell cohesion. Scientific reports. 2014; 4:7593.

20. Danilo C and Frank PG. Cholesterol and breast cancer development. Current opinion in pharmacology. 2012; 12(6):677-682.

21. dos Santos CR, Domingues G, Matias I, Matos J, Fonseca I, de Almeida JM and Dias S. LDL-cholesterol signaling induces breast cancer proliferation and invasion. Lipids in health and disease. 2014; 13:16.

22. Lagrost L. Regulation of cholesteryl ester transfer protein (CETP) activity: review of in vitro and in vivo studies. Biochimica et biophysica acta. 1994; 1215(3):209-236.

23. Cazita PM, Berti JA, Aoki C, Gidlund M, Harada LM, Nunes VS, Quintao EC and Oliveira HC. Cholesteryl ester transfer protein expression attenuates atherosclerosis in ovariectomized mice. Journal of lipid research. 2003; 44(1):33-40.

24. Cappel DA, Palmisano BT, Emfinger CH, Martinez MN, McGuinness OP and Stafford JM. Cholesteryl ester transfer protein protects against insulin resistance in obese female mice. Molecular metabolism. 2013; 2(4):457-467.

25. Izem L and Morton RE. Possible role for intracellular cholesteryl ester transfer protein in adipocyte lipid metabolism and storage. The Journal of biological chemistry. 2007; 282(30):21856-21865.

26. Tchoua U, D’Souza W, Mukhamedova N, Blum D, Niesor E, Mizrahi J, Maugeais C and Sviridov D. The effect of 
cholesteryl ester transfer protein overexpression and inhibition on reverse cholesterol transport. Cardiovascular research. 2008; 77(4):732-739.

27. Sagar S, Esau L, Moosa B, Khashab NM, Bajic VB and Kaur M. Cytotoxicity and apoptosis induced by a plumbagin derivative in estrogen positive MCF-7 breast cancer cells. Anti-cancer agents in medicinal chemistry. 2014; 14(1):170-180.

28. Checker R, Gambhir L, Sharma D, Kumar M and Sandur SK. Plumbagin induces apoptosis in lymphoma cells via oxidative stress mediated glutathionylation and inhibition of mitogen-activated protein kinase phosphatases (MKP1/2). Cancer letters. 2015; 357(1):265-278.

29. Eldhose B, Gunawan M, Rahman M, Latha MS and Notario V. Plumbagin reduces human colon cancer cell survival by inducing cell cycle arrest and mitochondria-mediated apoptosis. International journal of oncology. 2014; 45(5):1913-1920.

30. Xu KH and Lu DP. Plumbagin induces ROS-mediated apoptosis in human promyelocytic leukemia cells in vivo. Leukemia research. 2010; 34(5):658-665.

31. Zhou ZW, Li XX, He ZX, Pan ST, Yang Y, Zhang X, Chow K, Yang T, Qiu JX, Zhou Q, Tan J, Wang D and Zhou SF. Induction of apoptosis and autophagy via sirtuin1- and $\mathrm{PI} 3 \mathrm{~K} / \mathrm{Akt} / \mathrm{mTOR}$-mediated pathways by plumbagin in human prostate cancer cells. Drug design, development and therapy. 2015; 9:1511-1554.

32. Kontush A and Chapman MJ. Antiatherogenic small, dense HDL--guardian angel of the arterial wall? Nature clinical practice Cardiovascular medicine. 2006; 3(3):144-153.

33. Le Goff W, Guerin M and Chapman MJ. Pharmacological modulation of cholesteryl ester transfer protein, a new therapeutic target in atherogenic dyslipidemia. Pharmacology \& therapeutics. 2004; 101(1):17-38.

34. Richardson MA, Berg DT, Johnston PA, McClure D and Grinnell BW. Human liposarcoma cell line, SW872, secretes cholesteryl ester transfer protein in response to cholesterol. Journal of lipid research. 1996; 37(5):11621166.

35. Liu J, Xian G, Li M, Zhang Y, Yang M, Yu Y, Lv H, Xuan S, Lin Y and Gao L. Cholesterol oxidase from Bordetella species promotes irreversible cell apoptosis in lung adenocarcinoma by cholesterol oxidation. Cell death \& disease. 2014; 5:e1372.

36. Granot E, Tabas I and Tall AR. Human plasma cholesteryl ester transfer protein enhances the transfer of cholesteryl ester from high density lipoproteins into cultured HepG2 cells. The Journal of biological chemistry. 1987; 262(8):3482-3487.

37. Sukkasem N, Chatuphonprasert W, Tatiya-Aphiradee $\mathrm{N}$ and Jarukamjorn $\mathrm{K}$. Imbalance of the antioxidative system by plumbagin and Plumbago indica L. extract induces hepatotoxicity in mice. Journal of intercultural ethnopharmacology. 2016; 5(2):137-145.

38. Haddad SA, Lunetta KL, Ruiz-Narvaez EA, Bensen JT, Hong CC, Sucheston-Campbell LE, Yao S, Bandera EV, Rosenberg L, Haiman CA, Troester MA, Ambrosone CB and Palmer JR. Hormone-related pathways and risk of breast cancer subtypes in African American women. Breast cancer research and treatment. 2015; 154(1):145-154.

39. Shim JS, Li RJ, Lv J, Head SA, Yang EJ and Liu JO. Inhibition of angiogenesis by selective estrogen receptor modulators through blockade of cholesterol trafficking rather than estrogen receptor antagonism. Cancer letters. 2015; 362(1):106-115.

40. Lappano R, Recchia AG, De Francesco EM, Angelone T, Cerra MC, Picard D and Maggiolini M. The cholesterol metabolite 25-hydroxycholesterol activates estrogen receptor alpha-mediated signaling in cancer cells and in cardiomyocytes. PloS one. 2011; 6(1):e16631.

41. de Gonzalo-Calvo D, Lopez-Vilaro L, Nasarre L, PerezOlabarria M, Vazquez T, Escuin D, Badimon L, Barnadas A, Lerma E and Llorente-Cortes V. Intratumor cholesteryl ester accumulation is associated with human breast cancer proliferation and aggressive potential: a molecular and clinicopathological study. BMC cancer. 2015; 15:460.

42. Kaiser J. Cancer. Cholesterol forges link between obesity and breast cancer. Science (New York, NY). 2013; 342(6162): 1028 .

43. Poirot M, Silvente-Poirot $S$ and Weichselbaum RR. Cholesterol metabolism and resistance to tamoxifen. Current opinion in pharmacology. 2012; 12(6):683-689.

44. Rodrigues Dos Santos C, Fonseca I, Dias S and Mendes de Almeida JC. Plasma level of LDL-cholesterol at diagnosis is a predictor factor of breast tumor progression. BMC cancer. 2014; 14:132.

45. Kaur M and Esau L. Two-step protocol for preparing adherent cells for high-throughput flow cytometry. BioTechniques. 2015; 59(3):119-126.

46. Jafari R, Almqvist $\mathrm{H}$, Axelsson $\mathrm{H}$, Ignatushchenko M, Lundback T, Nordlund P and Martinez Molina D. The cellular thermal shift assay for evaluating drug target interactions in cells. Nature protocols. 2014; 9(9):21002122 .

47. Zhang JH, Chung TD and Oldenburg KR. A Simple Statistical Parameter for Use in Evaluation and Validation of High Throughput Screening Assays. J Biomol Screen. 1999; 4(2):67-73.

48. Goswami CP and Nakshatri H. PROGgene: gene expression based survival analysis web application for multiple cancers. Journal of Clinical Bioinformatics. 2013; 3(1):22. 